\title{
Synthesis and characterization of ferrocene containing block copolymers
}

Chernyy, Sergey; Wang, Zhongli; Kirkensgaard, Jacob Judas Kain; Bakke, Anders; Mortensen, Kell; Ndoni, Sokol; Almdal, Kristoffer

Published in:

Journal of Polymer Science. Part A, Polymer Chemistry

Link to article, DOI:

$10.1002 /$ pola.28435

Publication date:

2017

Document Version

Peer reviewed version

Link back to DTU Orbit

Citation (APA):

Chernyy, S., Wang, Z., Kirkensgaard, J. J. K., Bakke, A., Mortensen, K., Ndoni, S., \& Almdal, K. (2017).

Synthesis and characterization of ferrocene containing block copolymers. Journal of Polymer Science. Part A, Polymer Chemistry, 55(3), 495-503. https://doi.org/10.1002/pola.28435

\section{General rights}

Copyright and moral rights for the publications made accessible in the public portal are retained by the authors and/or other copyright owners and it is a condition of accessing publications that users recognise and abide by the legal requirements associated with these rights.

- Users may download and print one copy of any publication from the public portal for the purpose of private study or research.

- You may not further distribute the material or use it for any profit-making activity or commercial gain

- You may freely distribute the URL identifying the publication in the public portal

If you believe that this document breaches copyright please contact us providing details, and we will remove access to the work immediately and investigate your claim 


\title{
Synthesis and Characterization of Ferrocene Containing Block Copolymers
}

\author{
Sergey Chernyy, ${ }^{* 1}$ Zhongli Wang, ${ }^{1,2}$ Jacob Judas Kain Kirkensgaard, ${ }^{3}$ Anders Bakke, ${ }^{3}$ Kell Mortensen, ${ }^{3}$ \\ Sokol Ndoni, ${ }^{1,2}$ Kristoffer Almdal ${ }^{1,2}$ \\ ${ }^{1}$ Technical University of Denmark, DTU Nanotech - Department of Micro- and Nanotechnology, \\ Produktionstorvet, 2800 Kgs. Lyngby, Denmark
}

${ }^{2}$ Center for Nanostructured Graphene, CNG, DTU Nanotech - Department of Micro- and Nanotechnology, Produktionstorvet, 2800 Kgs. Lyngby, Denmark

${ }^{3}$ Niels Bohr Institute, University of Copenhagen, 2100 Copenhagen, Denmark

Correspondence to: Sergey Chernyy (E-mail: sergeychernyy@gmail.com)

Additional Supporting Information may be found in the online version of this article.

\begin{abstract}
Narrowly dispersed diblock copolymers containing poly(methyl methacrylate) [PMMA] or poly(nonafluorohexyl methacrylate) [PF9MA] as the first block and poly(ferrocenylmethyl methacrylate) [PFMMA] as the second block, were prepared by anionic polymerization for the first time. Disordered bulk morphologies in the case of PMMA- $b$-PFMMA were observed and explained in terms of low Flory-Huggins interaction parameter $(\chi \leq 0.04)$. In the case of PF9MA- $b$-PFMMA hexagonally packed cylinder morphology (HEX) was substantiated from TEM and SAXS observations. Furthermore, high incompatibility between PF9MA and PFMMA blocks allowed for the formation of well-ordered ferrocene containing cylinders on silica substrate upon exposure of the thin films to a saturated solvent vapor. It was shown that the cylinder orientation, parallel or perpendicular to the surface, could easily be controlled by appropriate choice of the solvent and without the need for preliminary surface modification, e.g. by means of grafted brush layer.

KEYWORDS: Ferrocenylmethyl methacrylate (FMMA), $1 \mathrm{H}, 1 \mathrm{H}, 2 \mathrm{H}, 2 \mathrm{H}$-nonafluorohexyl methacrylate (F9MA), anionic polymerization, diblock copolymers, Flory-Huggins interaction parameter, rheology, order-disorder transition.))
\end{abstract}

\section{INTRODUCTION}

Ferrocene based polymers are attractive due to such valuable metallocene-rendered properties as low toxicity, excellent one electron redox reversibility $^{1}$, magnetic susceptibility ${ }^{2-4}$, photoand semiconductivity ${ }^{5-9}$, ability to form polymeric charge-transfer complexes ${ }^{10,}{ }^{11}$, to quench triplet states ${ }^{11}$ etc. More specifically, the presence of organoiron moieties in the main polymer chain or in the side groups infer high glass transition temperature $\left(T_{\mathrm{g}}\right)$ of the resulting polymers mainly due to the high cohesive energy density of the ferrocenyl groups. ${ }^{11}$ The high $T_{\mathrm{g}}$ of ferrocene-containing polymers combined with their excellent plasma etch selectivity could be beneficial for, e.g., block copolymer lithography applications allowing for pattern formation at high temperatures. ${ }^{12,13}$ Moreover, the ability of ferrocene containing polymers to switch between II and III oxidation states was recently employed to create stimuli-responsive diblock copolymers and a controlled release of 
encapsulated compounds from poly(vinylferrocene)- $b$-poly(methyl methacrylate) [PVFc- $b$-PMMA] based micelles have been achieved by reversible oxidation of ferrocene to stable ferrocenium (ferricenium) cations. ${ }^{14-16}$

Most of the ferrocene containing polymers are currently produced by living anionic polymerization, RAFT, ATRP or free radical polymerization techniques. In the latter case the peroxide based free radical initiators should be excluded due to their possible reduction by ferrocene moieties resulting in low conversions. We selected anionic polymerization for the synthesis of diblock copolymers of ferrocenylmethyl methacrylate (FMMA) and methyl methacrylate (MMA) or FMMA and $1 H, 1 H, 2 H, 2 H$-nonafluorohexyl methacrylate (F9MA), with the aim to further investigate the bulk and surface morphologies of the resulting novel block copolymers by means of TEM, SEM, SAXS, Rheology and AFM.

To the best of our knowledge, no well-ordered morphologies for PFMMA containing diblock copolymers were reported in the up-to-date literature. Resent work by Gallei et al. on poly(styrene) [PS] block copolymers with PFMMA (PS- $b$-PFMMA) concludes that incomplete phase separation of PS and PFMMA blocks takes place presumably due to their good mutual compatibility. ${ }^{17}$ Cylindrical, spherical and lamellar morphologies for poly(ferrocenyldimethylsilane- $b$ -

dimethylsiloxane) (PFS-b-PDMS) and PS-b-PFS diblock copolymers of various composition were reported. ${ }^{4}$ Also, micellization of poly(isoprene- $b$ ferrocenylmethylsilane) (PI- $b$-PFMS) and PFS- $b$ PI was recently investigated. ${ }^{18,} 19$ Moreover, a complete overview of the synthesized polyferrocenylsilanes could be found in the excellent review by Manners et al. ${ }^{20}$

Thermodynamic incompatibility between the metallocene-containing block and the purely organic blocks was also assessed in the present work, although to a minor extent. Understanding the Flory-Huggins interaction parameter $(\chi)$ is important from both fundamental and application point of views since it allows to, e.g., design patterns with predetermined pitch and size of the organoiron domains, estimate the minimum molecular weight for a given diblock copolymer needed to be able to undergo the microphase separation, chose the right monomer for the second block in order to minimize or maximize the sharpness of the boundary between the microphases in a diblock copolymer. ${ }^{21}$

\section{EXPERIMENTAL}

All chemicals were purchased from SigmaAldrich unless otherwise stated. Tetrahydrofuran (THF) was distilled from ketyl radical of benzophenone under argon. Methyl methacrylate (MMA) was consecutively distilled from calcium hydride $\left(\mathrm{CaH}_{2}\right)$ and triethylaluminum ( $\left.\mathrm{AlEt}_{3}\right)$. Attempts to distill $1 \mathrm{H}, 1 \mathrm{H}, 2 \mathrm{H}, 2 \mathrm{H}$-nonafluorohexyl methacrylate (F9MA, TCl) from AlEt 3 were not successful due to onset of rapid polymerization; instead, F9MA was distilled twice from $\mathrm{CaH}_{2}$.

The molecular weight was determined by gel permeation chromatography (GPC) using THF with $1 \%$ triethylamine as an eluent at $0.5 \mathrm{ml} / \mathrm{min}$ flow rate with a column set consisting of aprecolumn and two $300 \times 8 \mathrm{~mm}$ main columns (PLgel Mixed C and Mixed D). Transmission electron microscopy (TEM) was performed on microtomed samples (60 $\mathrm{nm}$ thick) without staining using FEI Tecnai $\mathrm{T} 20 \mathrm{G}^{2}$ at $200 \mathrm{kV}$ in a bright field mode. For scanning electron microscopy (SEM) of the microphases on silica substrates a Zeiss Supra 40VP was used at $3 \mathrm{kV}$ accelerating voltage and $3-4 \mathrm{~mm}$ working distance. X-ray photoelectron spectroscopy (XPS) data were acquired on ThermoScientific XPS instrument equipped with an Al K-Alpha source of 1486 eV energy. Samples were analyzed using charge compensation from a flood gun in a vacuum not exceeding $10^{-7} \mathrm{mbar}$ with a spot size of $400 \times 400 \mu \mathrm{m}$. Rheological characterization was realized on a Rheometrics solids analyzer (RSA II) operated with a $0.3 \mathrm{~mm}$ gap shear sandwich configuration at $1 \%$ shear 
strain $(\gamma)$ amplitude and $1 \mathrm{rad} / \mathrm{s}$ frequency $(\omega)$. Small-angle X-ray scattering (SAXS) profiles were measured using the SAXSLab instrument at the Niels Bohr Institute (NBI). The SAXSLab instrument uses a Rigaku 40W micro-focused $\mathrm{Cu}$ source producing $\mathrm{X}$-rays with a wavelength of $1.54 \AA$ which is detected by a moveable Pilatus $300 \mathrm{k}$ pixel-detector. A sample was mounted in small Cu-discs between two 5-7 $\mu \mathrm{m}$ mica windows. The $q$ calibration of the instrument was done by using silver behenate as a reference.

$\mathrm{N}, \mathrm{N}$-dimethylaminomethylferrocene $\mathrm{e}^{22,}{ }^{23}$ was synthesized via aminomethylation of ferrocene with $\quad N, N, N^{\prime}, N^{\prime}$-tetramethylmethylenediamine (Scheme 1 ). In a typical run, ferrocene (46.4

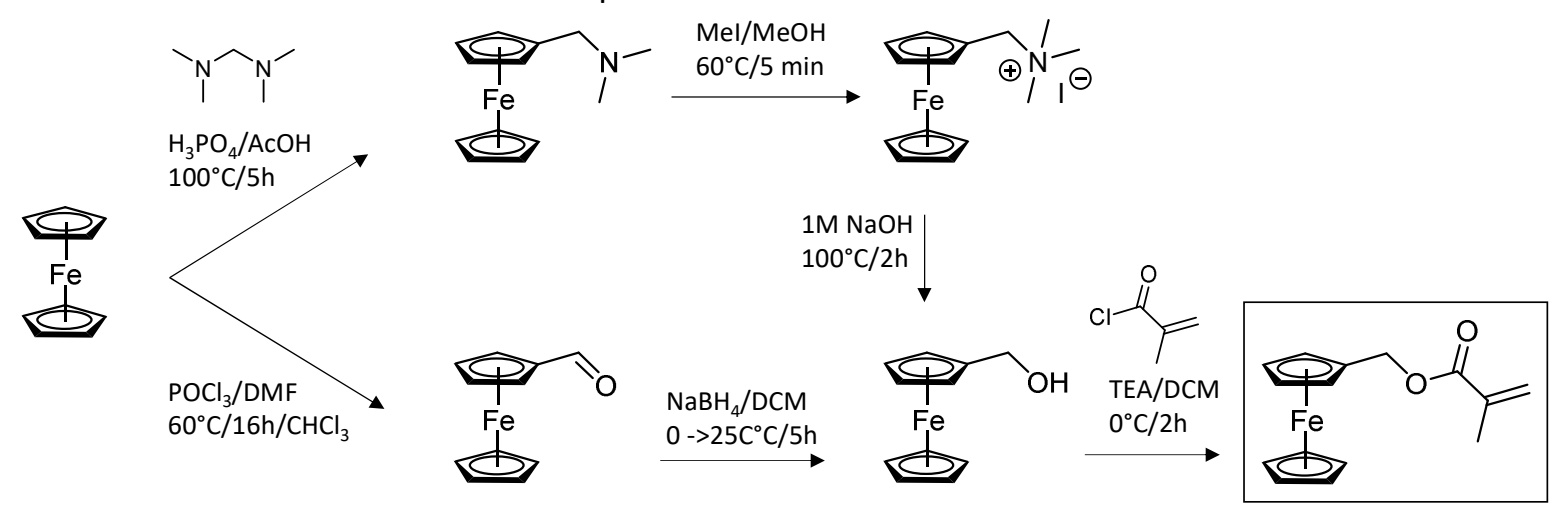

Scheme 1 Synthesis of Ferrocenylmethyl Methacrylate (FMMA)

g, $0.25 \mathrm{~mol}$ ) was added to the stirred mixture of $N, N, N^{\prime}, N^{\prime}$-tetramethylmethylenediamine $\quad(43.2$ g, $0.42 \mathrm{~mol}), \mathrm{H}_{3} \mathrm{PO}_{4}(43.2 \mathrm{~g}, 0.44 \mathrm{~mol})$ and acetic acid $(400 \mathrm{ml}, 6.99 \mathrm{~mol})$. The mixture color turned to dark amber upon heating to $100^{\circ} \mathrm{C}$ for $5 \mathrm{~h}$ (oil bath). The mixture was cooled to room temperature, diluted with water and neutralized with $275 \mathrm{~g} \mathrm{NaOH}$ while cooling with ice. After the extraction with diethyl ether the ethereal fractions were combined, 3 times washed with water, dried over $\mathrm{Na}_{2} \mathrm{SO}_{4}$ and concentrated on a rotary evaporator. Distillation of the product under reduced pressure afforded $36.3 \mathrm{~g}$ of $\mathrm{N}, \mathrm{N}$ dimethylaminomethylferrocene as a dark-red mobile liquid, yield $61 \% .{ }^{1} \mathrm{H}$ NMR $\left(\mathrm{CDCl}_{3}, 400\right.$ $\mathrm{MHz}$, in ppm): $4.10(\mathrm{~m}, 6 \mathrm{H}), 3.26(\mathrm{~d}, J=8.9 \mathrm{~Hz}$, $2 \mathrm{H}), 2.16(\mathrm{~d}, J=1.9 \mathrm{~Hz}, 6 \mathrm{H})$.

\section{$\mathrm{N}, \mathrm{N}$-dimethylaminomethylferrocene}

methiodide. ${ }^{23}$ Methyl iodide $(37.0 \mathrm{~g}, 0.26 \mathrm{~mol})$ was added dropwise to the solution of $\mathrm{N}, \mathrm{N}$ dimethylaminomethylferrocene (36.3 g, 0.15 mol) in $50 \mathrm{ml}$ methanol. The mixture was refluxed for 5 minutes followed by addition of $400 \mathrm{ml}$ diethyl ether. The resulting yellow crystals were filtered and dried affording $57 \mathrm{~g}$ of the product, yield $97 \% .{ }^{1} \mathrm{H} \mathrm{NMR}\left(\mathrm{CDCl}_{3}, 400 \mathrm{MHz}\right.$, in ppm): $4.90(\mathrm{~s}, 2 \mathrm{H}), 4.57(\mathrm{~m}, 2 \mathrm{H}), 4.34(\mathrm{~m}, 2 \mathrm{H})$, $4.30(\mathrm{~s}, 5 \mathrm{H}), 3.31(\mathrm{~s}, 9 \mathrm{H})$.

Ferrocenecarboxaldehyde. ${ }^{24} \mathrm{POCl}_{3}(75 \mathrm{ml}, 0.8$ mol) was added slowly to dimethyl formamide (150 ml, $1.95 \mathrm{~mol}$ ) while cooling with ice. After $15 \mathrm{~min}$ the mixture was diluted with $200 \mathrm{ml}$ of chloroform and ferrocene $(50 \mathrm{~g}, 0.27 \mathrm{~mol})$ was added. The dark amber mixture was stirred at $60{ }^{\circ} \mathrm{C}$ for $16 \mathrm{~h}$. Ice water $(1 \mathrm{~L})$ was slowly added to the cooled reaction mixture followed by $70 \mathrm{~g}$ of $\mathrm{NaOH}$ and $215 \mathrm{~g}$ of sodium acetate. The product was extracted with $1 \mathrm{~L}$ of chloroform, washed three times with water and concentrated. The tar was removed by flushing the product though a silica column (hexane:acetone 5:1) affording $35 \mathrm{~g}$ of crimson crystals, yield $61 \%$. ${ }^{1} \mathrm{H} \mathrm{NMR}\left(\mathrm{CDCl}_{3}, 400 \mathrm{MHz}\right.$, in ppm): $9.95(\mathrm{~s}, 1 \mathrm{H}), 4.79(\mathrm{~s}, 2 \mathrm{H}), 4.60(\mathrm{~s}, 2 \mathrm{H}), 4.27$ $(\mathrm{s}, 5 \mathrm{H})$. Ferrocenemethanol from $\mathbf{N}, \mathbf{N}$ -
dimethylaminomethylferrocene methiodide. ${ }^{23}$ A solution of sodium hydroxide ( $1 \mathrm{M}, 500 \mathrm{ml}, 0.5$ mol) was added to $\mathrm{N}, \mathrm{N}$ - 
dimethylaminomethylferrocene methiodide (57 $\mathrm{g}, 0.15 \mathrm{~mol})$. The resulting slurry was refluxed at $110{ }^{\circ} \mathrm{C}$ (oil bath) for $2 \mathrm{~h}$, cooled to room temperature and acidified with $45 \mathrm{ml}$ of $37 \% \mathrm{HCl}$ diluted in $100 \mathrm{ml}$ of water. $\mathrm{NaHCO}_{3}$ was slowly added until neutral $\mathrm{pH}$. The mixture was extracted with $1 \mathrm{~L}$ of dichloromethane and concentrated. Recrystallization of the crude product from hexane afforded $15 \mathrm{~g}$ of highly pure (TLC) hydroxymethyl ferrocene in a form of yellow needles, yield $47 \%$. ${ }^{1} \mathrm{H}$ NMR $\left(\mathrm{CDCl}_{3}, 400\right.$ $\mathrm{MHz}$, in ppm): $4.31(\mathrm{~s}, 2 \mathrm{H}), 4.28(\mathrm{~s}, 2 \mathrm{H}), 4.24$ (s, 7H), $1.47(\mathrm{~s}, 1 \mathrm{H})$.

\section{Ferrocenemethanol}

from

ferrocenecarboxaldehyde. ${ }^{17}$ To the solution of ferrocenecarboxaldehyde $(29.0 \mathrm{~g}, 0.14 \mathrm{~mol})$ in $900 \mathrm{ml}$ methanol $\mathrm{NaBH}_{4}(13.5 \mathrm{~g}, 0.36 \mathrm{~mol})$ was added within $2 \mathrm{~h}$ at $0{ }^{\circ} \mathrm{C}$. Slightly brown mixture was warmed up to room temperature and stirred for additional $3 \mathrm{~h}$. $1 \mathrm{~L}$ of saturated $\mathrm{NH}_{4} \mathrm{Cl}$ solution was added resulting in a yellow-brown slurry. After $16 \mathrm{~h}$ the product was extracted with $800 \mathrm{ml}(4 \times 200 \mathrm{ml})$ dichloromethane, washed three times with $300 \mathrm{ml}$ water, dried over $\mathrm{Na}_{2} \mathrm{SO}_{4}$ and concentrated affording $28.5 \mathrm{~g}$ of the ferrocenemethanol, yield $97 \% .{ }^{1} \mathrm{H}$ NMR $\left(\mathrm{CDCl}_{3}\right.$, $400 \mathrm{MHz}$, in ppm): $4.31(\mathrm{~s}, 2 \mathrm{H}), 4.28(\mathrm{~s}, 2 \mathrm{H}), 4.24$ $(\mathrm{s}, 7 \mathrm{H}), 1.47(\mathrm{~s}, 1 \mathrm{H})$.

Ferrocenylmethyl Methacrylate (FMMA). ${ }^{25}, 26$ Methacryloyl chloride $(16 \mathrm{ml}, 0.16 \mathrm{~mol})$ in $100 \mathrm{ml}$ of dry dichloromethane (DCM) was added dropwise to the mixture of dry triethylamine ( 25 $\mathrm{ml}, 0.18 \mathrm{~mol})$ and ferrocenemethanol $(23.2 \mathrm{~g}$, $0.11 \mathrm{~mol}$ ) in $400 \mathrm{ml}$ of dry DCM. The reaction mixture was stirred for $2 \mathrm{~h}$ at $0{ }^{\circ} \mathrm{C}$ and then $2 \mathrm{~h}$ at room temperature. The precipitant was filtered and DCM fraction was washed with 200 $\mathrm{ml}$ of the saturated $\mathrm{NaHCO}_{3}, 200 \mathrm{ml}$ of brine and water $(10 \times 200 \mathrm{ml})$, dried over $\mathrm{Na}_{2} \mathrm{SO}_{4}$ and concentrated on rotary evaporator at $30{ }^{\circ} \mathrm{C}$ in the dark. Addition of $10 \mathrm{ml}$ of hexane to the dark red liquid initiated crystallization of the product. After 1 day at $+4{ }^{\circ} \mathrm{C} 22.5 \mathrm{~g}$ of FMMA was recovered in a form of bright orange crystals, yield $74 \%$. ${ }^{1} \mathrm{H} \mathrm{NMR}\left(\mathrm{CDCl}_{3}, 400 \mathrm{MHz}\right.$, in $\left.\mathrm{ppm}\right)$ : $6.11(\mathrm{~m}, 1 \mathrm{H}), 5.55(\mathrm{~m}, 1 \mathrm{H}), 4.96(\mathrm{~s}, 2 \mathrm{H}), 4.29(\mathrm{~m}$, 2H) $4.18(\mathrm{~m}, 7 \mathrm{H}) 1.95(\mathrm{~s}, 3 \mathrm{H})$.

Anionic polymerization. The polymerizations were realized using a procedure described elsewhere. ${ }^{27}$ Briefly, for the synthesis of PMMA$b$-PFMMA diblock copolymer with a total molecular weight of $24 \mathrm{kDa}$, having a volume fraction of PFMMA block of 55\%, abbreviated further as $\mathrm{PM}_{24 \mathrm{k}} \mathrm{F}_{55}$, the following step sequence was adopted. A solution of MMA (0.7 g) in THF was added to the mixture of SBuLi-DPE initiator $(0.062 \mathrm{mmol})$ and $\mathrm{LiCl}(0.31 \mathrm{mmol}, 5 x$ relative to initiator) in $200 \mathrm{ml} \mathrm{THF}$ at $-78^{\circ} \mathrm{C}$. After $1 \mathrm{~h}$ a THF solution of $0.8 \mathrm{~g}$ FMMA was added. After additional $1 \mathrm{~h}$ the living chains were terminated with $2 \mathrm{ml}$ of degassed $\mathrm{MeOH}$ and the mixture was precipitated into $0.5 \mathrm{~L}$ of isopropanol followed by filtration and drying at $80^{\circ} \mathrm{C}$ for $16 \mathrm{~h}$ at $1 \mathrm{e}-3 \mathrm{mbar}$. Yellow solid product was thereby obtained in a quantitative yield (Scheme2) 

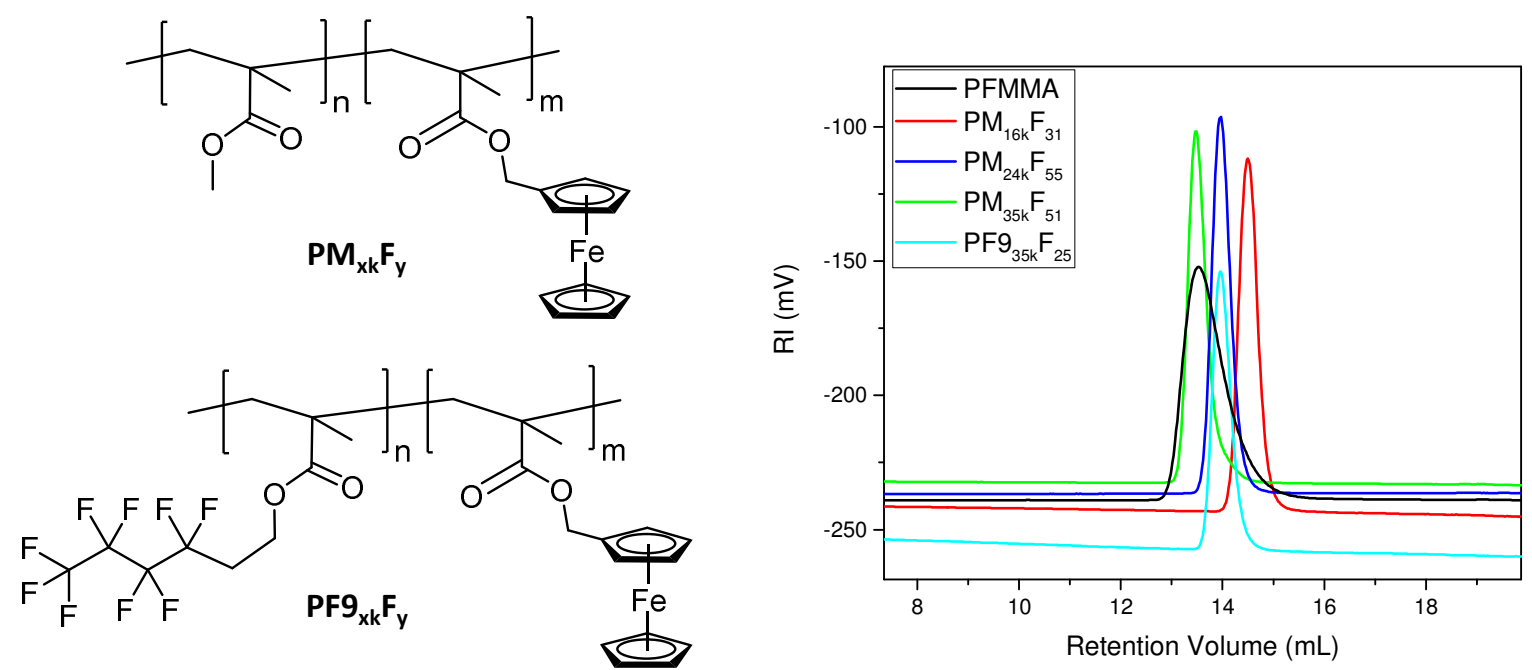

Scheme 2 (left) chemical structures of the PMMA- $b$-PFMMA (PM $\left.{ }_{\mathrm{xk}} \mathrm{F}_{\mathrm{y}}\right)$ and PF9MA- $b$-PFMMA (PF9 $\left.{ }_{\mathrm{xk}} \mathrm{F}_{\mathrm{y}}\right)$ diblock copolymers and (right) the corresponding GPC curves. In the name of the sample the first subscript denotes total molecular weight of the diblock copolymer while the second subscript signifies the average (from NMR and TGA) volume fraction (in \%) of the PFMMA block

\section{RESULTS AND DISCUSSION}

The synthesis of FMMA monomer was realized in two different approaches (Scheme 1). In Route 1, the initial ferrocene was aminomethylated and the introduced dimethylamino group was subsequently quaternized and hydrolysed affording the precursor compound, ferrocenemethanol. ${ }^{22,}{ }^{23}$ In the second route, ferrocene was converted to ferrocenecarboxaldehyde in Vilsmeier-Haak formylation conditions and aldehyde group was mildly reduced to alcohol giving the same ferrocenemethanol precursor. ${ }^{17,} 24,28$ Finally, by acylation of ferrocenemethanol with methacryloyl chloride the targeted FMMA was produced. ${ }^{25,26}$ The second route appears to be more attractive due to reduced number of steps required and commercial availability of the ferrocenecarboxaldehyde, which would further shorten the time required for the synthesis.

Block copolymer synthesis was realized by sequential addition of the monomers to the initiator solution. First, MMA was polymerized and then a solution of FMMA in THF was added to the living PMMA-Li chains. Such sequence was chosen because PMMA-Li chains are more nucleophilic than PFMMA-Li due to the stabilizing effect of ferrocenylmethyl substituent on forming carbanion. ${ }^{29}$ For $\mathrm{PF}_{35 \mathrm{k}} \mathrm{F}_{25}$ the sequence was inversed since the perfluoroalkyl substituent is expected to exert a higher electron withdrawing effect compared to the ferrocenylmethyl group. As a result, a series of block copolymers with molecular weights in the range 15-35 $\mathrm{kDa}$ and polydispersities 1.02-1.04 were successfully synthesized (Table 1 ). 
TABLE 1 Characteristics of the synthesized PFMMA homopolymer and block copolymers.

\begin{tabular}{|c|c|c|c|c|c|c|c|}
\hline Name $^{a}$ & $\begin{array}{l}\text { MW, } \\
\text { kDa } \\
\text { (NMR) }\end{array}$ & $\begin{array}{l}\text { DP } 1^{\text {st }} \\
\text { block }^{\text {b }}\end{array}$ & $\begin{array}{l}\text { DP } \\
\text { PFMMA }\end{array}$ & $\begin{array}{l}\text { PDI } \\
\text { (GPC) }\end{array}$ & $\begin{array}{l}\text { Residue } \\
\text { at } \\
900^{\circ} \mathrm{C}, \%\end{array}$ & $\begin{array}{l}f_{\text {PFMMA }} \\
\text { (NMR) }\end{array}$ & $\begin{array}{l}f_{\text {PFMMA }} \\
\text { (TGA) }\end{array}$ \\
\hline PFMMA & 45.8 & - & 161 & 1.15 & 25.1 & 1.00 & 1.00 \\
\hline $\mathrm{PM}_{16 \mathrm{k}} \mathrm{F}_{31}$ & 15.5 & 103 & 19 & 1.03 & 9.5 & 0.31 & 0.31 \\
\hline $\mathrm{PM}_{24 \mathrm{k}} \mathrm{F}_{55}$ & 24.4 & 101 & 50 & 1.02 & 15.9 & 0.56 & 0.53 \\
\hline $\mathrm{PM}_{35 k} \mathrm{~F}_{51}$ & 35.2 & 149 & 71 & 1.04 & 14.2 & 0.54 & 0.47 \\
\hline $\mathrm{PF}_{35 \mathrm{k}} \mathrm{F}_{25}$ & 35.2 & 81 & 26 & 1.03 & 6.1 & 0.25 & 0.25 \\
\hline
\end{tabular}
a In the name of the sample the first subscript denotes total molecular weight of the diblock copolymer while the second subscript
signifies the average (from NMR and TGA) volume fraction (in \%) of the PFMMA block.

${ }^{\mathrm{b}}$ Degree of polymerization of the first block.

TGA. The thermal stability of the synthesized block copolymers was found to be strongly dependent on the nature of the first block. In the case of PFMMA homopolymer, the temperature corresponding to the maximum rate of decomposition ( $\left.T_{\max }\right)$ is equal to $454^{\circ} \mathrm{C}$ (Figure 1 ). For the diblock copolymer with PMMA stability decreases by $65-87^{\circ} \mathrm{C}\left(T_{\max }=389^{\circ} \mathrm{C}\right.$ for $\mathrm{PM}_{24 \mathrm{k}} \mathrm{F}_{55}$ and $367^{\circ} \mathrm{C}$ for $\left.\mathrm{PM}_{16 \mathrm{k}} \mathrm{F}_{31} / \mathrm{PM}_{35 \mathrm{k}} \mathrm{F}_{51}\right)$. Furthermore, a $187^{\circ} \mathrm{C}$ decrease in stability $\left(T_{\max }=267^{\circ} \mathrm{C}\right)$ was observed for PF9MA containing diblock copolymer presumably due to facile formation of nonafluorohex-1-ene and cyclic esters upon PF9MA block degradation. ${ }^{30}$

Furthermore, the residue after the thermal degradation of block copolymers in air was analyzed by means of XPS and was found to consist of pure $\mathrm{Fe}_{2} \mathrm{O}_{3}$ (Supporting Information, SI1). By taking into account the molecular weight of the iron (III) oxide we can use the data on the TGA residue to calculate the volume fraction of the PFMMA block and therefore independently assess the composition of the block copolymer. As seen from the last two columns of Table 1, the volume fractions of PFMMA block ( $f_{\text {PFMMA }}$ ) calculated from the TGA residues and by NMR are in good agreement.

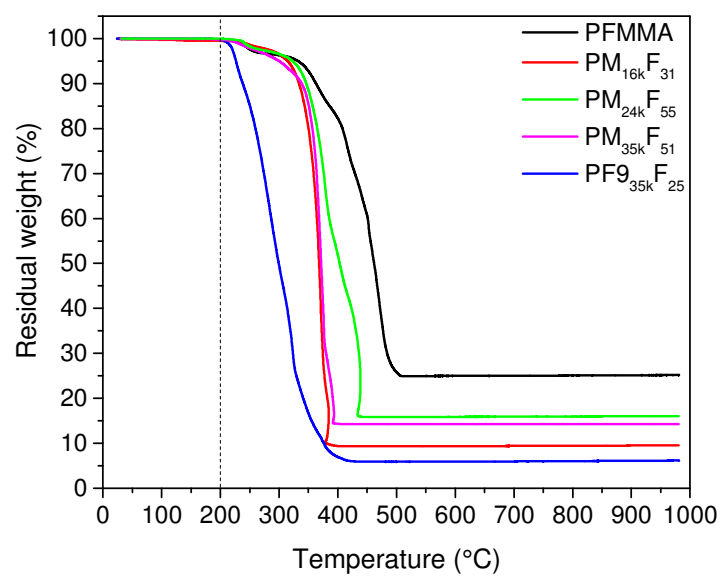

Figure 1. TGA curves of the synthesized block copolymers in air (flow $=60 \mathrm{ml} / \mathrm{min}$ ) recorded at $10^{\circ} \mathrm{C} / \mathrm{min}$ heating rate.

Rheology. Isochronal temperature scans $s^{31-33}$ for the poly(ferrocenylmethyl methacrylate) (PFMMA) homopolymer and diblock copolymers are presented in Figure 2. The dynamical mechanical spectrum of PFMMA is in general agreement with the data for low molecular weight uncrosslinked polymers. ${ }^{34}$ The polymer behaves as a true viscoelastic solid up to $160{ }^{\circ} \mathrm{C}$ since the elasticity $\left(\sim G^{\prime}\right)$ is higher than viscosity ( $\left.G^{\prime \prime}\right)$ whereas viscous behavior starts to dominate at higher temperatures. No rubbery plateau, expected to occur within $10^{3}-10^{4} \mathrm{~Pa}$, was detected after the softening indicating that the molecular weight of PFMMA (45.8 $\mathrm{kDa})$ is lower that the double critical entanglement molecular weight $\left(2 \mathrm{Me}_{\mathrm{e}}\right)$. Considering typical 
values of $M_{\mathrm{e}}$ for poly(styrene), i.e. $13-19 \mathrm{kDa},{ }^{27}$, 35 we suggest that bulky ferrocenylmethyl substituents prevent the formation of intermacromolecular entanglements even at relatively high molecular weight of PFMMA (45.8 $\mathrm{kDa}$ ). Above $210^{\circ} \mathrm{CPFMMA}$ starts to be unstable and undergoes decomposition and crosslinking reactions which results in the increase of both $G^{\prime}$ and $G^{\prime \prime}$.

PMMA containing block copolymers of low molecular weight $\left(\mathrm{PM}_{16 k} \mathrm{~F}_{31}\right.$ and $\left.\mathrm{PM}_{24 k} \mathrm{~F}_{55}\right)$ demonstrate similar transitions during the temperature ramp indicating the absence of the ordered microphase separated morphologies. In the case of $P M_{35 k} F_{51}$ sample, $G^{\prime}$ and $G^{\prime \prime}$ almost overlaps which could be explained by a decreased mobility of the chains in this relatively high molecular weight diblock copolymer.

On the contrary, $\mathrm{PF}_{35 \mathrm{k}} \mathrm{F}_{25}$ sample of identical molecular weight undergoes microphase separation (ordering) below $140{ }^{\circ} \mathrm{C}$ as could be inferred from the higher values of $G^{\prime}$ compared to $G$ ". The rearrangement of the chains during the transition process is facilitated by the low $T_{g}$ of the PF9MA block $\left(29{ }^{\circ} \mathrm{C}\right)$ [Supporting Information, SI5] which imparts high chain mobility and fast relaxation processes. The formation of the ordered morphology is complete at $180{ }^{\circ} \mathrm{C}$ and the formed microstructure persists up to $220^{\circ} \mathrm{C}$ due to high incompatibility between the blocks. Limited thermal stability precludes a direct observation of the order-disorder transition (segmental mixing) which is typically characterized by a sharp decrease of both $G^{\prime}$ and $G^{\prime \prime}$ to almost zero values. Overall, the characteristic rheological signature observed herein corresponds to the hexagonally packed cylinder morphology and it is in agreement with the literature reported rheological data ${ }^{36}$ as well as SAXS (Supporting Information, SI7) and TEM data (Figure 3).

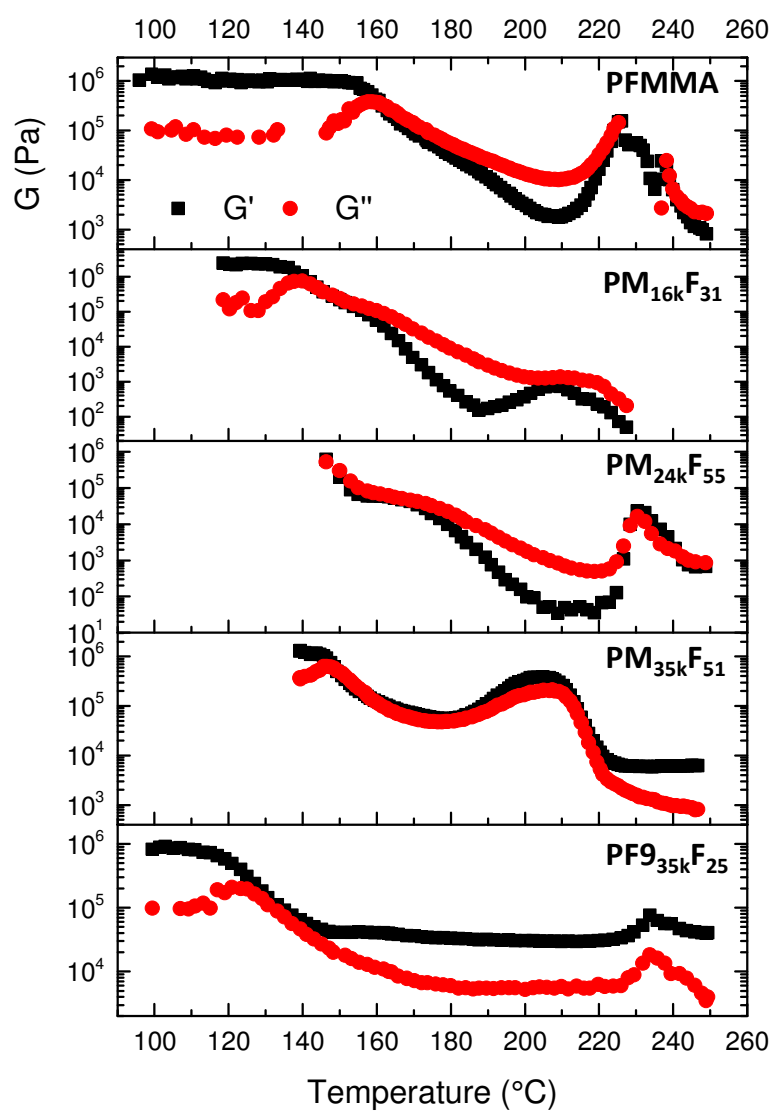

Figure 2 Isochronal ( $\omega=1 \mathrm{rad} / \mathrm{s})$ dynamic storage $\left(G^{\prime}\right)$ and loss $\left(G^{\prime \prime}\right)$ moduli measured at $2{ }^{\circ} \mathrm{C} / \mathrm{min}$ heating rate and constant shear strain $(\gamma=1 \%)$. The data below ca. $160^{\circ} \mathrm{C}$ are not reliable due to instrumental limitations in measuring high modulus values and the transitions above ca. $200{ }^{\circ} \mathrm{C}$ are not reversible due to polymer degradation.

Different solubilities of the homopolymers from which a given diblock copolymer is composed could give an indirect indication of their mutual compatibility. We found that ethyl acetate, while being a good solvent for PMMA, swells but does not dissolve PFMMA. Such drastic difference in the solubility of two homopolymers is a positive indication of their mutual incompatibility. Sample $\mathrm{PM}_{16 k} \mathrm{~F}_{31}$ (PMMA-b-PFMMA) however has a disordered morphology, as discussed earlier. Low molecular weight of the constituent blocks ( $5 \mathrm{kDa}-10.5 \mathrm{kDa}$ ) could explain this observation. For a given block copolymer the 
incompatibility of the blocks is characterized by a product of Flory-Huggins interaction parameter $(X)$ and the number of segments $(N)$, $\chi N$. For a given composition, $\chi$ is constant (at constant temperature) and the immiscibility of two blocks could only be increased by producing higher molecular weight block copolymer to increase $N$.

The absolute $\chi$ value for PFMMA- $b$-PMMA is not known. For somewhat similar block copolymer of poly(styrene- $b$-ferrocenyldimethylsilane) [PS$b$-PFDMS] the reported $\chi$ is equal to 0.032 at 150 ${ }^{\circ} \mathrm{C}$ which is almost identical to well-known weakly segregating PS- $b$-PMMA block copolymer $\left(X=0.030\right.$ at $\left.150{ }^{\circ} \mathrm{C}\right) .{ }^{21,} 37$ Furthermore, the
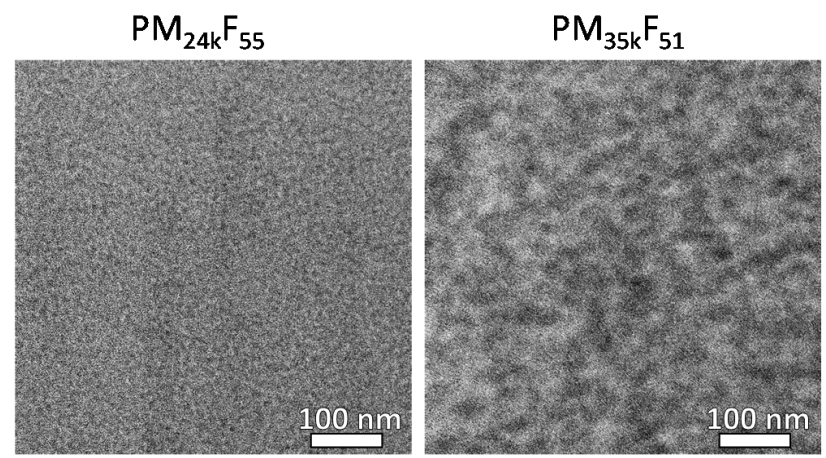

microphase separation in PS- $b$-PFMMA was shown to be incomplete due to considerable compatibility between PS and PFMMA. ${ }^{17}$ It is thus reasonable to assume that PFMMA- $b$ PMMA would have very low incompatibility (if any) which necessitates the synthesis of high molecular weight polymer for verifying that assumption.

We therefore synthesized block copolymers having higher molecular weight. Samples $\mathrm{PM}_{24 k} \mathrm{~F}_{55}$ and $\mathrm{PM}_{35 \mathrm{k}} \mathrm{F}_{51}$ are clearly disordered, however, they have local composition fluctuations in a form of alternating dark (enriched with PFMMA) and bright (enriched with PMMA) areas (Figure 3 ).

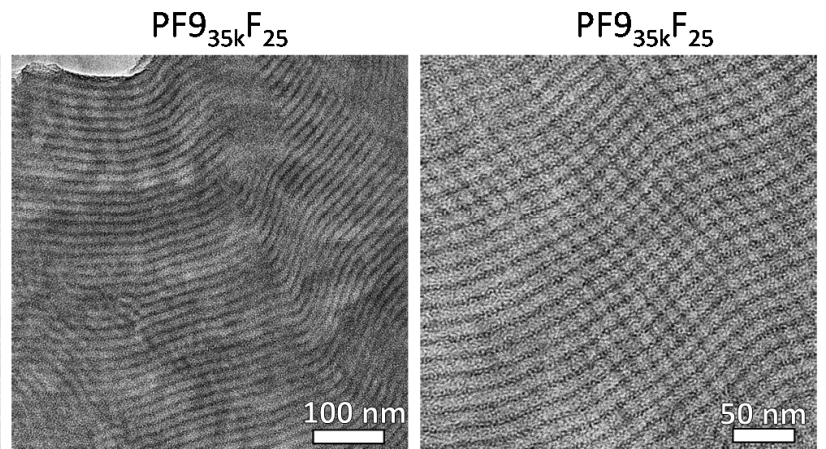

Figure 3 TEM images of the block copolymers. Samples were heat annealed at $160^{\circ} \mathrm{C}$ for $65 \mathrm{~h}$ in vacuum then microtomed to $60 \mathrm{~nm}$ films and observed by TEM without staining.

The absence of the homogeneous segmentally mixed states characterized by $\chi N \ll 10$ for PFMMA- $b$-PMMA samples indicate that $\chi N \leq 10$ and therefore we can estimate the upper boundary for the $\chi$ value as described below. ${ }^{38}$ For the sample of $24.4 \mathrm{kDa}$ the molecular weights of PMMA and PFMMA blocks are 10.2 and $14.2 \mathrm{kDa}$ (from NMR) which after division with the densities of PMMA $\left(1.18 \mathrm{~g} / \mathrm{cm}^{3}\right)$ and PFMMA $\left(1.37 \mathrm{~g} / \mathrm{cm}^{3}\right)$ yield the volumes of one mole of PMMA and PFMMA blocks (8683 and $10370 \mathrm{~cm}^{3} / \mathrm{mol}$ respectively). After division with Avogadro number the volumes of one PMMA and PFMMA blocks become equal to 14.4 and $17.2 \mathrm{~nm}^{3}$ respectively. Taking into account the standard reference volume ${ }^{21}$ of the statistical segment $N\left(=0.118 \mathrm{~nm}^{3}\right)$, the $N_{\text {PMMA }}$ and $N_{\text {PFMMA }}$ would be equal to 142 and 146 units, while the total $N$ amounts to 268 units. Considering $\chi N \leq$ 10 we estimate the upper boundary of the FloryHuggins interaction parameter, that is, $\chi \leq 0.04$ for PMMA- $b$-PFMMA diblock copolymer of 24.4 kDa at $160^{\circ} \mathrm{C}$.

Surface morphologies. Block copolymer selfassembly is a powerful platform for nanolithography. However, most of the block copolymer lithography processes need preliminary surface modification, including grafting of a neutral polymer brush layer onto the substrate to balance the surface interactions with two blocks of a given diblock copolymer. ${ }^{39-}$ ${ }^{41}$ Here we present a procedure that could potentially simplify the main stream block copolymer lithography process. ${ }^{42} \quad \mathrm{PF}_{35 \mathrm{k}} \mathrm{F}_{25}$ copolymer was directly applied on silicon 
substrate without any pretreatment by spincoating from $0.1 \mathrm{wt}$. \% toluene solution at 2000 rpm for 30 seconds to give a $12 \mathrm{~nm}$ thin film.

The morphologies formed at different conditions of solvent vapor annealing were investigated by SEM and AFM. Figure 4a, b, c show top view SEM images of $\mathrm{PFO}_{35 k} \mathrm{~F}_{25}$ after three different conditions of annealing. The ordering behavior exhibits strong solvent dependence and the difference in the solubility of the PFMMA and PF9MA blocks gives a possibility to further manipulate the domain size and separation distances in thin films.

A morphology of well-ordered lying cylinders with $19 \mathrm{~nm}$ period is clearly seen upon annealing in saturated solvent vapor of ethyl acetate for 20 minutes (Figure 4). The $19 \mathrm{~nm}$ period is in a good agreement with an equilibrium domain spacing (d) which was estimated by SAXS to be equal to $19.3 \mathrm{~nm}$. This observation points out to the fact that the polymer chains forming cylinders parallel to the surface are in non-frustrated state. ${ }^{43}$ When ethyl acetate /THF ( $\left./ \mathrm{v}=5 / 1\right)$ mixture was used for the solvent annealing for 20 minutes, a mixed morphology containing cylinders of both parallel and perpendicular orientations was observed (Figures $4 b, e$ ).
Furthermore, well-ordered hexagonally packed cylinders perpendicular to the substrate surface were observed when the film was annealed in pure THF vapor for 20 minutes (Figures 4c, f). The reason for the change in the orientation of morphologies in different annealing solvent vapors can be explained in terms of the difference in solvent selectivity and solvent saturated vapor pressure. ${ }^{44}$ The perpendicular orientation of HEX morphology requires the underlying surface to be neutral. Since ethyl acetate only swells but does not dissolve the PFMMA block it could be considered a more selective solvent for the PF9MA block. Therefore, in the presence of a selective solvent (ethyl acetate) the surface interactions are screened to a larger extent for PF9MA block but not for PFMMA block and, thus, specific adsorption of the PFMMA onto the substrate induces parallel cylinder orientation. On the contrary, when nonspecific solvent is present (THF) both blocks are well solvated, their mutual segment-segment interactions become screened to a certain extent while their surface interactions appear to be totally balanced ("neutral surface") resulting in the perpendicular with respect to the substrate orientation of the cylinders.
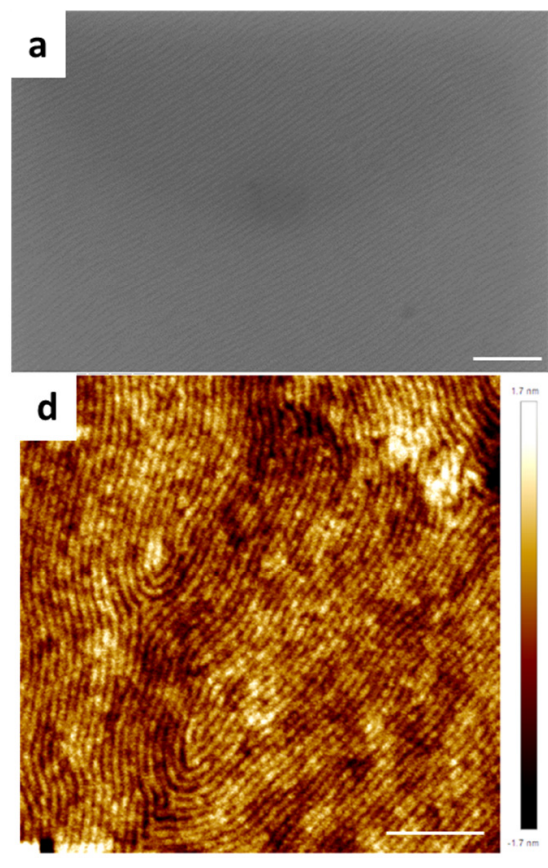
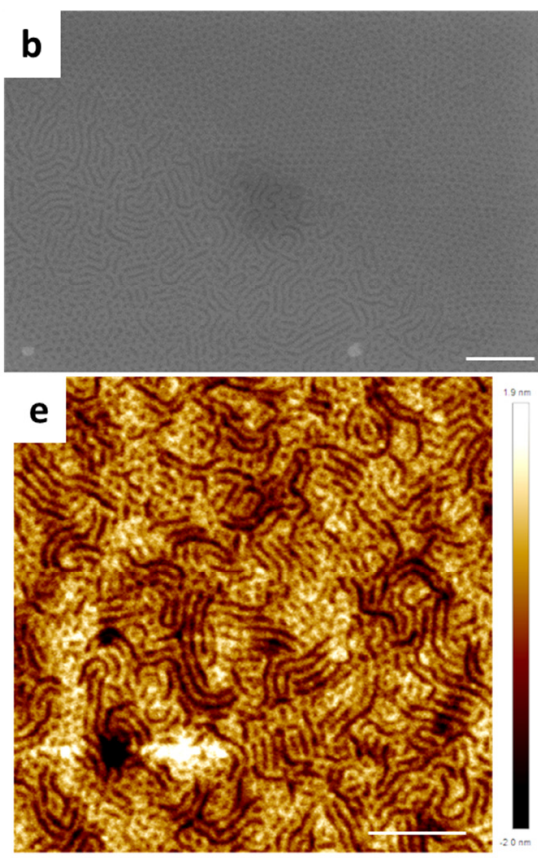
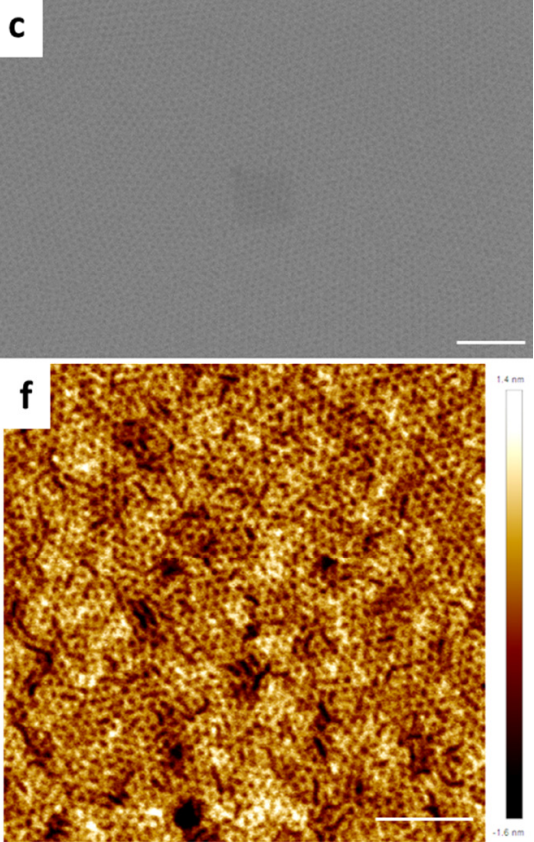
Figure 4 SEM (top-row) and AFM (bottom-row) images of $\mathrm{PF}_{35} \mathrm{~K}_{25}$ on $\mathrm{SiO}_{2} / \mathrm{Si}$ substrate after annealing for $20 \mathrm{~min}$ in (a, d) ethyl acetate atmosphere, (b, e) EA/THF atmosphere and (c, f) THF atmosphere. Scale bars correspond to $100 \mathrm{~nm}$.

XPS. As to the elemental composition of the $\mathrm{PF}_{35 \mathrm{~K}} \mathrm{~F}_{25}$ thin films, expected from the block copolymer structure C (45.5 At.\%), O (10.6 At.\%), $\mathrm{F}(38.3 \mathrm{At} . \%)$ and Fe (1.6 At.\%) elements as well as small amount of Si (4.0 At.\%) originating from the underlying substrate were found on the surface. Interestingly, the relative intensities and binding energies (BE) of $\mathrm{C} 1 \mathrm{~s}$ core electrons reflect the presence of six different carbon atoms containing substituents of varied polarity (Figure 5) in high resolution (HR) XPS. The peak A at the highest BE $294.1 \mathrm{eV}$ represents the most "electronegative" - $\mathrm{CF}_{3}$ carbon and constitute $7 \%$ of the total C1s intensity which is in a good agreement with theoretically predicted $7 \%$ intensity. The prediction of the relative contributions from the 6 different carbons were made by taking into account the 3.09:1.00 PF9MA:FMMA monomer unit ratio in the $\mathrm{PF}_{35 \mathrm{k}} \mathrm{F}_{25}$ block copolymer structure obtained from NMR. The peak B at $291.7 \mathrm{eV}(20 \%$ vs. 21 $\%$ theory) corresponds to

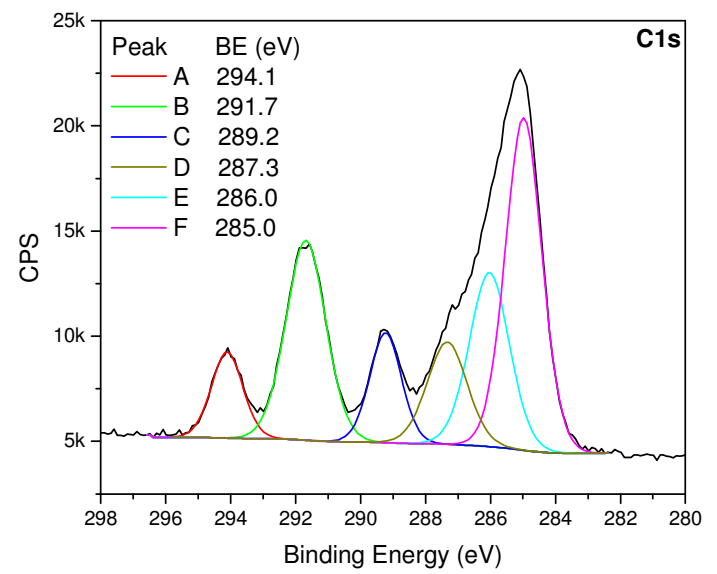

Figure 5 C1s HR XPS peak fitting for the PF9 ${ }_{35 k} \mathrm{~F}_{25}$ thin film on silica substrate. the three $-\mathrm{CF}_{2^{-}}$atoms. The carbonyl $\mathrm{C}=\mathrm{O}$ is located at $289.2 \mathrm{eV}$ ( $9 \%$ vs. $9 \%$ theory) and has an equal contribution from the ester groups of two monomers. The D ( $16 \%$ vs. $11 \%$ theory) and E (15\% vs. $19 \%$ theory) peaks at moderately low $\mathrm{BE}$ are typically ascribed to the carbon atoms with less polar substituents, such as -C-O-, tertiary carbons in the polymer backbone and tree carbons in the substituted cyclopentadienyl ring of the ferrocene. At last, the peak F ( $33 \%$ vs. $33 \%$ theory) could be unambiguously attributed to the $-\mathrm{CH}_{2-}^{-},-\mathrm{CH}_{3}$ groups in the backbone and five $-\mathrm{CH}=$ carbons of the unsubstituted cyclopentadienyl ring. ${ }^{45-47}$

Oxygen plasma etching. In order to demonstrate the concept of the plasma etch resistance of the ferrocene-containing polymers in general, we analyzed the etch selectivity of the PFMMA homopolymer (Table 2). By conducting the plasma etching at high pressure, we observe highly anisotropic etching and inefficient removal of the carbon from the organometallic block. Reducing the pressure $\sim 3$ times afforded higher ion energy ${ }^{48}$ in the plasma which, in turn, facilitated physical sputtering and removal of the organic material from the layer. As a result, underlying silicon substrate becomes detectable by XPS already after 2 min of the oxygen plasma etching. Importantly, a significant amount of Fe remains on the surface and is not removed by oxygen plasma. By comparing the $\mathrm{C} / \mathrm{Fe}$ ratio before and after $10 \mathrm{~min}$ etching at $0.36 \mathrm{mbar}$ we estimated 17 times higher etch resistivity of the forming iron oxide with respect to the organic fraction of the PFMMA.

Table 2. XPS survey data in atomic percents (At.\%) for the PFMMA films before and after exposure to oxygen plasma at varied pressure and time. 


\begin{tabular}{lllllll}
\hline Time, min & $\begin{array}{l}\text { Pressure, } \\
\text { mbar }\end{array}$ & $\mathrm{Si}, \mathrm{At} . \%$ & $\mathrm{C}, \mathrm{At} . \%$ & $\mathrm{O}, \mathrm{At} . \%$ & $\mathrm{Fe}, \mathrm{At} . \%$ & $\mathrm{C} / \mathrm{Fe}$ \\
\hline Theory, PFMMA & - & 0 & 83.3 & 11.1 & 5.6 & 15.0 \\
\hline 0 & 0 & 0.0 & 81.9 & 11.3 & 6.8 & 12.1 \\
\hline & 1 & 0.0 & 40.0 & 45.0 & 15.0 & 2.7 \\
\hline 2 & 1 & 0.0 & 38.2 & 45.6 & 16.3 & 2.3 \\
\hline 5 & 1 & 0.0 & 32.2 & 49.7 & 18.1 & 1.8 \\
\hline 10 & 1 & 0.0 & 26.5 & 54.3 & 19.2 & 1.4 \\
1 & 0.36 & 0.0 & 25.2 & 54.5 & 20.3 & 1.2 \\
\hline 2 & 0.36 & 9.9 & 11.2 & 58.1 & 20.8 & 0.5 \\
\hline 5 & 0.36 & 11.1 & 13.4 & 57.0 & 18.5 & 0.7 \\
\hline 10 & 0.36 & 20.0 & 10.5 & 54.8 & 14.6 & 0.7 \\
\hline
\end{tabular}

The presence of the iron (III) oxide was confirmed by high resolution (HR) XPS. Peaks at lower binding energy corresponding to the nonoxidized ferrocenylmethyl methacrylate ( $\mathrm{Fe} 2 \mathrm{p}_{3 / 2}$ $=707.6$ and $\mathrm{Fe} 2 \mathrm{p}_{1 / 2}=720.4 \mathrm{eV}$ ) appear to be shifted to the higher binding energy corresponding to $\mathrm{Fe}_{2} \mathrm{O}_{3}\left(\mathrm{Fe} 2 \mathrm{p}_{3 / 2}=710.9\right.$ and $\mathrm{Fe}$ $2 \mathrm{p}_{1 / 2}=724.5 \mathrm{eV}, \Delta=13.6 \mathrm{eV}$ ) after oxygen plasma treatment. ${ }^{49-51}$ Also, appearance of the shake-up satellites characteristic for $\mathrm{Fe}_{2} \mathrm{O}_{3}$ is clear from Figure $6 .{ }^{52}$

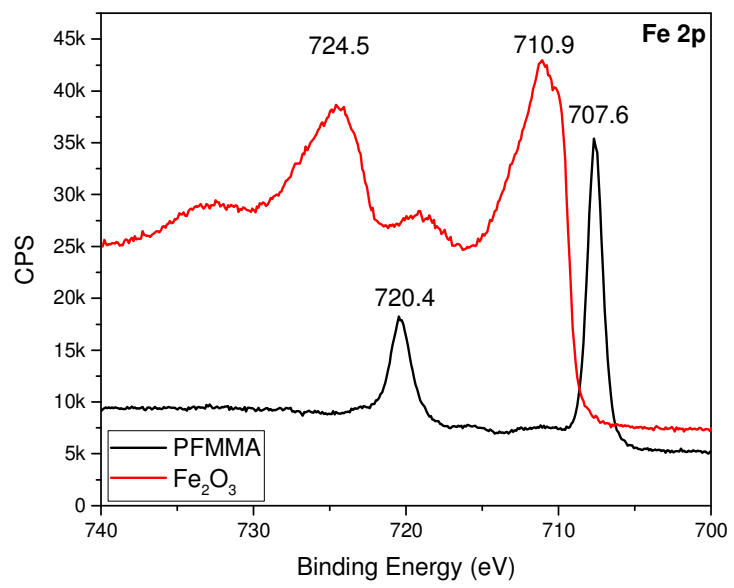

Figure 6 HR XPS spectra of Fe $2 \mathrm{p}$ for the PFMMA thin film ( $2 \mathrm{wt} . \%$ in toluene, $3 \mathrm{krpm}$ ) before (black curve) and after (red curve) being exposed to oxygen plasma for $10 \mathrm{~min}(0.36 \mathrm{mbar}, 50 \mathrm{~W})$. 


\section{CONCLUSIONS}

The core findings of the work lend support to the following conclusions. Poly(methyl methacrylate) [PMMA] and poly(nonafluorohexyl methacrylate (PF9MA) diblock copolymers with poly(ferrocenylmethyl methacrylate) [PFMMA] could be produced solely by the anionic polymerization route affording well-defined products $(P D I=1.02-$ 1.04). In the case of PMMA- $b$-PFMMA samples with molecular weight $16000-35000 \mathrm{~g} / \mathrm{mol}$, good compatibility $(\chi \leq 0.04)$ between two blocks results in the absence of phase separation, as confirmed by rheology and TEM. On the contrary, when perfluorinated methacrylate was used in one of the blocks (PF9MA-b-PFMMA), the phase separation was easily attainable up to

\section{ACKNOWLEDGEMENTS}

Authors are thankful to Villum Foundation for the financial support of the project. Support by the Danish National Research Foundation,

\section{REFERENCES AND NOTES}

1. Tamura, K.; Akutagawa, N.; Satoh, M.; Wada, J.; Masuda, T. Macromol. Rapid Commun. 2008, 29, (24), 1944-1949.

2. Posselt, D.; Badur, W.; Steiner, M.; Baumgarten, M. Synth. Met. 1993, 56, (2), 32993304.

3. Hmyene, M.; Yassar, A.; Escorne, M.; Percheron-Guegan, A.; Garnier, F. Adv. Mater. 1994, 6, (7-8), 564-568.

4. Massey, J. A.; Power, K. N.; Winnik, M. A.; Manners, I. Adv. Mater. 1998, 10, (18), 15591562. the degradation temperature of the diblock copolymer indicating high incompatibility. PFMMA homopolymer was shown to form $\mathrm{F}_{2} \mathrm{O}_{3}$ on the surface upon plasma etching which entails further applicability of the microphase separated thin films based on PF9MA- $b$-PFMMA copolymer. Such nanostructured films could potentially provide an access to either nanocylinders or nanodots of photoactive $\mathrm{Fe}_{2} \mathrm{O}_{3}$ on the substrate with high surface area and aspect ratio. These properties are highly desirable in the field of solar energy conversion. ${ }^{53}$ We plan to further elaborate on the intriguing properties and applicability of ferrocene containing polymers in the upcoming publications.

Project DNRF103 is acknowledged. SC expresses gratitude to prof. Niels B. Larsen for the helpful suggestions about plasma etching experiments.
5. Yasuda, H.; Noda, I.; Miyanaga, S.; Nakamura, A. Macromolecules 1984, 17, (11), 2453-2454.

6. Cyr, P. W.; Tzolov, M.; Manners, I.; Sargent, E. H. Macromol. Chem. Phys. 2003, 204, (7), 915-921.

7. $\quad$ Cowan, D. O.; Park, J.; Pittman, C. U.; Sasaki, Y.; Mukherjee, T. K.; Diamond, N. A. J. Am. Chem. Soc. 1972, 94, (14), 5110-5112.

8. Espada, L.; Pannell, K. H.; Papkov, V.; Leites, L.; Bukalov, S.; Suzdalev, I.; Tanaka, M.; Hayashi, T. Organometallics 2002, 21, (18), 3758-3761. 
9. Bakueva, L.; Sargent, E. H.; Resendes, R.; Bartole, A.; Manners, I. J. Mater. Sci. Mater. Electron. 2001, 12, (1), 21-25.

10. Abd-El-Aziz, A. S.; Todd, E. K. Coord. Chem. Rev. 2003, 246, (1-2), 3-52.

11. Pittman, C. U.; Lai, J. C.; Vanderpool, D. P.; Good, M.; Prado, R. Macromolecules 1970, 3, (6), 746-754.

12. Korczagin, I.; Lammertink, R. G. H.; Hempenius, M. A.; Golze, S.; Vancso, G. J., Surface Nano- and Microstructuring with Organometallic Polymers. In Ordered Polymeric Nanostructures at Surfaces, Vancso, G. J., Ed. Springer Berlin Heidelberg: Berlin, Heidelberg, 2006; pp 91-117.

13. Lammertink, R. G. H.; Hempenius, M. A.; Chan, V. Z. H.; Thomas, E. L.; Vancso, G. J. Chem. Mater. 2001, 13, (2), 429-434.

14. Schmidt, B. V. K. J.; Elbert, J.; BarnerKowollik, C.; Gallei, M. Macromol. Rapid Commun. 2014, 35, (7), 708-714.

15. Staff, R. H.; Gallei, M.; Mazurowski, M.; Rehahn, M.; Berger, R.; Landfester, K.; Crespy, D. ACS Nano 2012, 6, (10), 9042-9049.

16. Gallei, M.; Klein, R.; Rehahn, M. Macromolecules 2010, 43, (4), 1844-1854.

17. Gallei, M.; Schmidt, B. V.; Klein, R.; Rehahn, M. Macromol. Rapid Commun. 2009, 30, (17), 1463-1469.

18. Du, V. A.; Qiu, H.; Winnik, M. A.; Whittell, G. R.; Manners, I. Macromol. Chem. Phys. 2016, 217, (15), 1671-1682.

19. Hayward, D. W.; Whittell, G. R.; Gilroy, J. B.; Manners, I.; Richardson, R. M. Liq. Cryst. 2016, 43, (8), 1148-1159.

20. Hailes, R. L. N.; Oliver, A. M.; Gwyther, J.; Whittell, G. R.; Manners, I. Chem. Soc. Rev. 2016, 45, (19), 5358-5407.

21. Sinturel, C.; Bates, F. S.; Hillmyer, M. A. ACS Macro Letters 2015, 4, (9), 1044-1050. 22. Lednicer, D.; Hauser, C. R. Org. Synth. 1960, 40, 31.

23. Lindsay, J. K.; Hauser, C. R. J. Org. Chem. 1957, 22, (4), 355-358.

24. Jia, J.; Cui, Y.; Li, Y.; Sheng, W.; Han, L.; Gao, J. Dyes Pigm. 2013, 98, (2), 273-279.

25. Lai, J. C.; Rounsefell, T. D.; Pittman, C. U. Macromolecules 1971, 4, (2), 155-161.
26. Nguema Edzang, R. W.; Lejars, M.; Brisset, H.; Raimundo, J. M.; Bressy, C. RSC Adv. 2015, 5, (94), 77019-77026.

27. Schulz, M. F.; Khandpur, A. K.; Bates, F. S.; Almdal, K.; Mortensen, K.; Hajduk, D. A.; Gruner, S. M. Macromolecules 1996, 29, (8), 2857-2867.

28. Broadhead, G.; Osgerby, J.; Pauson, P. J. Chem. Soc. (Resumed) 1958, 650-656.

29. Matsuo, Y.; Oie, T.; Goseki, R.; Ishizone, T.; Sugiyama, K.; Hirao, A. Macromol. Symp. 2013, 323, (1), 26-36.

30. Böker, A.; Reihs, K.; Wang, J.; Stadler, R.; Ober, C. K. Macromolecules 2000, 33, (4), 1310-1320.

31. Zhao, J.; Majumdar, B.; Schulz, M. F.; Bates, F. S.; Almdal, K.; Mortensen, K.; Hajduk, D. A.; Gruner, S. M. Macromolecules 1996, 29, (4), 1204-1215.

32. Foerster, S.; Khandpur, A. K.; Zhao, J.; Bates, F. S.; Hamley, I. W.; Ryan, A. J.; Bras, W. Macromolecules 1994, 27, (23), 6922-6935.

33. Adams, J. L.; Graessley, W. W.; Register, R. A. Macromolecules 1994, 27, (21), 60266032.

34. Wilbert, G.; Wiesemann, A.; Zentel, R. Macromol. Chem. Phys. 1995, 196, (11), 37713788.

35. Brandrup, J.; Immergut, E. H.; Grulke, E. A.; Abe, A.; Bloch, D. R., Polymer Handbook (4th Edition). John Wiley \& Sons: 2003; p 2336.

36. Cloitre, M.; Vlassopoulos, D., Block Copolymers in External Fields: Rheology, FlowInduced Phenomena, and Applications. In Applied Polymer Rheology, John Wiley \& Sons, Inc.: 2011; pp 209-239.

37. Eitouni, H. B.; Balsara, N. P.; Hahn, H.; Pople, J. A.; Hempenius, M. A. Macromolecules 2002, 35, (20), 7765-7772.

38. Bates, F. S. Science 1991, 251, (4996), 898-905.

39. Park, M.; Harrison, C.; Chaikin, P. M.; Register, R. A.; Adamson, D. H. Science 1997, 276, (5317), 1401-1404.

40. Bang, J.; Jeong, U.; Ryu, D. Y.; Russell, T. P.; Hawker, C. J. Adv. Mater. 2009, 21, (47), 4769-4792. 
41. Albert, J. N. L.; Epps lii, T. H. Mater. Today 2010, 13, (6), 24-33.

42. Li, T.; Wang, Z.; Schulte, L.; Ndoni, S. Nanoscale 2016, 8, (1), 136-140.

43. Fasolka, M. J.; Banerjee, P.; Mayes, A. M.; Pickett, G.; Balazs, A. C. Macromolecules 2000, 33, (15), 5702-5712.

44. Phillip, W. A.; Hillmyer, M. A.; Cussler, E. L. Macromolecules 2010, 43, (18), 7763-7770. 45. Watts, J. F. Surf. Interface Anal. 1993, 20, (3), 267-267.

46. Chernyy, S.; Ulah, S.; Sørensen, G.; Tordrup, S. W.; Pedersen, P. B.; Almdal, K. J. Appl. Polym. Sci. 2015, 132, (19), 41955.

47. Chernyy, S.; Jensen, B. E. B.; Shimizu, K.; Ceccato, M.; Pedersen, S. U.; Zelikin, A. N.; Daasbjerg, K.; Iruthayaraj, J. J. Colloid Interface Sci. 2013, 404, (0), 207-214.
48. Hartney, M. A.; Hess, D. W.; Soane, D. S. J. Vac. Sci. Technol. B 1989, 7, (1), 1-13.

49. Grosvenor, A.; Kobe, B.; Biesinger, M.; McIntyre, N. Surf. Interface Anal. 2004, 36, (12), 1564-1574.

50. Briggs, D., Handbook of X-ray Photoelectron Spectroscopy Heyden \& Son Ltd.: Minnesota, USA, 1979; p 190.

51. Paul, R.; Reifenberger, R. G.; Fisher, T. S.; Zemlyanov, D. Y. Chem. Mater. 2015, 27, (17), 5915-5924.

52. Weiss, W.; Ranke, W. Prog. Surf. Sci. 2002, 70, (1-3), 1-151.

53. Martinson, A. B. F.; DeVries, M. J.; Libera, J. A.; Christensen, S. T.; Hupp, J. T.; Pellin, M. J.; Elam, J. W. J. Phys. Chem. C 2011, 115, (10), 4333-4339.

\section{AUTHOR NAMES}

Sergey Chernyy, Zhongli Wang, Jacob Judas Kain Kirkensgaard, Anders Bakke, Kell Mortensen, Sokol Ndoni, Kristoffer Almdal

TITLE

Synthesis and Characterization of Ferrocene Containing Block Copolymers

TEXT

Diblock copolymer consisting of the perfluorinated and metallocene containing block was found to undergo microphase separation which results in the formation of the hexagonally packed cylinder morphology with the equilibrium domain spacing $19.3 \mathrm{~nm}$. 
GRAPHICAL ABSTRACT FIGURE
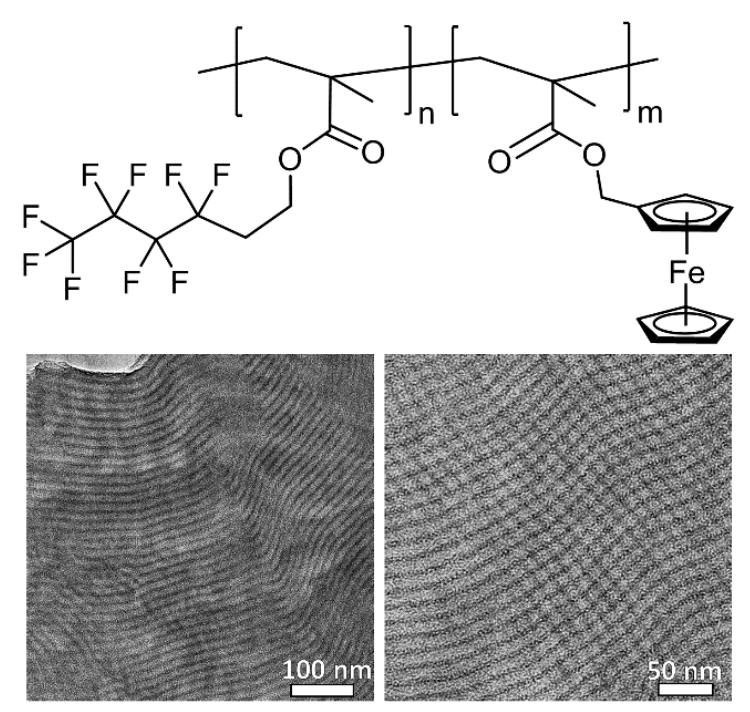